\title{
Management of menorrhagia in primary care-impact on referral and hysterectomy: data from the Somerset Morbidity Project
}

\author{
Clare Grant, Lesley Gallier, Tom Fahey, Nicky Pearson, Joyshri Sarangi
}

\begin{abstract}
Objective-To investigate the management of menorrhagia in primary care and its impact on referral and hysterectomy rates.

Design-Prospective observational study. Setting-11 general practices from the Somerset Morbidity Project.

Subjects-885 women consulting their general practitioner with menorrhagia over four years.

Main outcome measures-Proportions of these women investigated and treated with drugs in primary care, referred to a gynaecologist and undergoing operative procedures. The relation between investigation and prescribing in primary care and referral to and surgery in secondary care.

Results-Less than half of women had a vaginal examination $(42 \%, 95 \%$ CI $39 \%$ to $45 \%)$, or a full blood count $(39 \%, 95 \%$ CI $36 \%$ to $43 \%$ ). Almost a quarter of women, $23 \%(95 \%$ CI $20 \%$ to $26 \%)$, received no drugs and $37 \%$ (95\% CI $34 \%$ to $40 \%)$ received norethisterone. Over a third, $38 \%$ ( $95 \%$ CI $34 \%$ to $40 \%)$, of women were referred, and once referred $43 \%$ (95\% CI $38 \%$ to $48 \%$ ) of women were operated on. Women referred to a gynaecologist were significantly more likely to have received tranexamic acid and/or mefenamic acid in primary care $\left(\chi^{2}=16.4, \mathrm{df}=1, \mathrm{p}<0.001\right)$. There were substantial between practice variations in management, for example in prescribing of tranexamic acid and/or mefenamic acid (range $16 \%$ to $72 \%$ ) and referral to gynaecology (range $24 \%$ to $52 \%)$. There was a significant association between high referral and high operative rates (Spearman's correlation coefficient $=0.86, p=0.001$ ).

Conclusions-Substantial differences in management exist between practices when investigating and prescribing for menorrhagia in primary care. Rates of prescribing of effective medical treatment remain low. The decision to refer a woman impacts markedly on her chances of subsequently being operated on. Effective management in primary care may not reduce referral or hysterectomy rates. (F Epidemiol Community Health 2000;54:709-713)
\end{abstract}

Menorrhagia, defined as excessive menstrual loss of greater than $80 \mathrm{ml}$ per period, ${ }^{1}$ has a significant impact on many women's lives, as well as workload in primary and secondary care. Over $5 \%$ of women aged 30-49 years consult their general practitioner each year with this complaint. ${ }^{2}$ Menorrhagia accounts for $12 \%$ of gynaecology referrals, ${ }^{1}$ and once referred surgical intervention is highly likely. In one study $60 \%$ of women underwent a hysterectomy within five years of referral. ${ }^{3}$ The treatment objective in menorrhagia is to improve quality of life by alleviating heavy menstrual flow. According to recent guidelines, general practitioners should offer at least one course of effective drug therapy before referral for gynaecological opinion. ${ }^{4}$ Contraceptive requirements and preference for hormonal or non-hormonal drugs should influence the types of medical treatment offered.

The August 1995 edition of the Effective Health Care Bulletin, widely circulated among general practitioners, reviewed the evidence on the management of menorrhagia. ${ }^{1}$ It found that tranexamic acid and mefenamic acid are among the most effective treatments, whereas norethisterone is the least effective. However, in the United Kingdom norethisterone remains the most commonly prescribed drug for menorrhagia in primary care, and mefenamic acid and tranexamic acid are prescribed less often. ${ }^{2}$ The levonorgestrel releasing intrauterine device has also been shown to be effective, ${ }^{5}$ but is only licensed for contraceptive use in the UK. It can be used for menorrhagia if contraception is also required.

There are wide variations in referral patterns for menorrhagia and in population-based rates of hysterectomy. ${ }^{36}$ It has been suggested that the effective medical management of menorrhagia may impact on referral and subsequent hysterectomy rates. ${ }^{1}$ In Scandinavia, where tranexamic acid is the most widely used drug for menorrhagia, the hysterectomy rate is less than half that in the UK. ${ }^{7}$ With the introduction of effective management guidelines in New Zealand, savings have been anticipated on the basis of a reduction in the numbers of hysterectomies. ${ }^{8}$ However, such assumptions are based on extrapolation from ecological studies, and no evidence exists regarding the relation between effective medical management, referral and operative rates from patientbased studies.

Using data from the Somerset Morbidity Project, ${ }^{9}$ the aims of this study were to determine how effectively menorrhagia is investigated and treated in primary care, particularly since publication of the Effective Health Care Bulletin. ${ }^{1}$ We also sought to 
Table 1 Management of women with menorrhagia in primary and secondary care $(n=885)$

\begin{tabular}{ll}
\hline Investigation/drug/referral/operation & $\begin{array}{c}\text { \% all women } \\
\text { (range for } 11 \text { practices) }\end{array}$ \\
\hline Vaginal examination & $41.8(28.8$ to 68.2$)$ \\
Full blood count & $39.3(32.4$ to 45.3$)$ \\
Pelvic ultrasound scan & $12.5(3.8$ to 25.4$)$ \\
Tranexamic acid & $14.7(6.3$ to 56.3$)$ \\
Mefenamic acid & $26.6(10.9$ to 42.2$)$ \\
Tranexamic and/or mefenamic acid & $37.2(15.6$ to 71.9$)$ \\
Norethisterone & $37.2(20.3 \text { to } 57.8)^{\star}$ \\
Levonorgestrel releasing intrauterine device & $2.1(0.0$ to 6.3$)$ \\
Gynaecology referral & $37.6(24.4$ to 51.6$)$ \\
Endometrial sampling (by pipelle or hysteroscopy) & $16.4(7.7$ to 7.5$)$ \\
Dilatation and curettage (D\&C) & $5.4(1.3$ to 12.8$)$ \\
Transcervical resection of endometrium (TCRE) & $2.5(1.3$ to 3.4$)$ \\
Hysterectomy & $15.5(7.8$ to 22.7$)$ \\
\hline
\end{tabular}

$\star$ Data missing for one practice.

investigate between practice differences in management, the relation between prescribing in primary care, referral and operation in secondary care and lastly any secular changes in prescribing over a four year period.

\section{Methods}

THE SOMERSET MORBIDITY PROJECT

The 11 Somerset Morbidity Project practices are representative of the Somerset Health Authority population for general practice and population characteristics. ${ }^{9}$ The practices collect patient-based morbidity data, relating to a total patient population of 65000 , which has a high level of completeness (96\%) and validity $(87 \%) .{ }^{9}$ Each patient encounter is recorded by means of a Read code. In this study, practices provided patient-based data about drugs prescribed and investigations carried out for menorrhagia, referrals to gynaecology and operations carried out in secondary care.

DATA COLLECTION

The Morbidity Information Query and Export Syntax (MIQUEST) software was used, ${ }^{10}$ which searches and anonymises GP systems data while enabling event linkage by generating a unique reference code. The search was applied to data from the practices from April 1994 to April 1998. The records of all female patients aged 30 to 49 years were searched for a diagnosis of menorrhagia using Read codes (codes used available from authors). The enquiry identified all related Read codes for these patients, for consultations, investigations and prescribing for menorrhagia and gynaecology referrals and subsequent surgical interventions.
This is the first time the Morbidity Project has been used to link data on diagnosis with data on investigation, prescribing, referral and operation for a given condition. To ensure completeness and quality, the general practitioner notes of the women identified by the MIQUEST search were reviewed with regard to the diagnosis and management of menorrhagia (by CG, LG and TF). The notes of 885 $(93 \%)$ women were reviewed (the remainder were not registered with morbidity project practices at the end of the study period, so their notes were not available for validation purposes). The prevalence of menorrhagia was determined from the numbers of women identified by the MIQUEST search. It is the validated data, from the 885 patient records, which is used to describe the management of menorrhagia in this study.

\section{DATA ANALYSIS}

\section{Prevalence and management}

The number and proportion of women in the 11 practices consulting with a diagnosis of menorrhagia over four years were calculated. From this information age specific rates (30-49 years) of menorrhagia were determined. Management in primary care was described in terms of the numbers and proportions of women investigated (vaginal examination, full blood count and pelvic ultrasound scan), given a prescription (tranexamic acid, mefenamic acid, norethisterone, levonorgestrel releasing intrauterine device and other drugs) and referred to secondary care. Subsequent investigations (dilatation and curettage or endometrial sampling) and operations (hysterectomy or transcervical endometrial resection) in secondary care were also described.

Relation between management in primary care, referrals and operations

Investigation and prescribing in primary care were compared according to whether or not women were referred to secondary care, and also whether or not women referred were subsequently operated on, using the $\chi^{2}$ test.

\section{Between practice differences}

The practices were ranked for rates of prescribing, investigation, referral, operation and endometrial sampling procedures. Spearman's rank correlation coefficients were calculated to examine the relations between these variables.

Table 2 Investigation of and prescribing for women referred to and operated on in secondary care

\begin{tabular}{|c|c|c|c|c|c|}
\hline For all women $(n=885)$ & $\begin{array}{l}\text { Women referred } \\
n(\%)\end{array}$ & $\begin{array}{l}\text { Women not referred } \\
n(\%)\end{array}$ & $\begin{array}{l}\text { Difference in } \\
\text { proportions } \\
(\%)\end{array}$ & $\begin{array}{l}95 \% \text { CI for } \\
\text { difference }\end{array}$ & $p$ Value \\
\hline Vaginal examination & $172(51.7)$ & $198(35.9)$ & 15.8 & 9.1 to 22.5 & $<0.001$ \\
\hline Full blood count & $172(51.7)$ & $176(31.9)$ & 19.8 & 13.1 to 26.4 & $<0.001$ \\
\hline Pelvic ultrasound scan & $67(20.1)$ & $44(8.0)$ & 12.1 & 7.3 to 17.0 & $<0.001$ \\
\hline No medical treatment & $52(15.6)$ & $150(27.2)$ & 11.6 & 6.2 to 16.9 & $<0.001$ \\
\hline Tranexamic acid and/or mefenamic acid & $152(45.6)$ & $177(32.1)$ & 13.6 & 7.0 to 20.2 & $<0.001$ \\
\hline For women referred $(n=333)$ & $\begin{array}{l}\text { Women operated } \\
\text { on } n(\%)\end{array}$ & $\begin{array}{l}\text { Women not operated } \\
\text { on } n(\%)\end{array}$ & $\begin{array}{l}\text { Difference in } \\
\text { proportions } \\
(\%)\end{array}$ & $\begin{array}{l}95 \% \text { CI for } \\
\text { difference }\end{array}$ & $p$ Value \\
\hline No medical treatment & $20(14.0)$ & $32(16.8)$ & 2.8 & -4.9 to 10.6 & 0.48 \\
\hline Tranexamic acid and/or mefenamic acid & $68(47.6)$ & $84(44.2)$ & 3.3 & -7.5 to 14.2 & 0.54 \\
\hline
\end{tabular}


Secular trends

The Effective Health Care Bulletin was published in August 1995. ${ }^{1}$ To investigate its impact on the medical management of menorrhagia in primary care, rates of prescribing of tranexamic acid, mefenamic aid and norethisterone in each six month period between April 1994 and April 1998 were calculated, and secular changes explored by the $\chi^{2}$ test for trend.

Analysis of the validation data was done using SPSS, EPI-INFO and CIA software packages.

\section{Results}

PREVALENCE AND MANAGEMENT

The total number of women aged 30-49 years registered with the 11 practices was 9251 . During the four year period $954(10.3 \%)$ of these women consulted their general practitioner and were diagnosed as having menorrhagia (mean age 40 years, (SD 5.48)). The
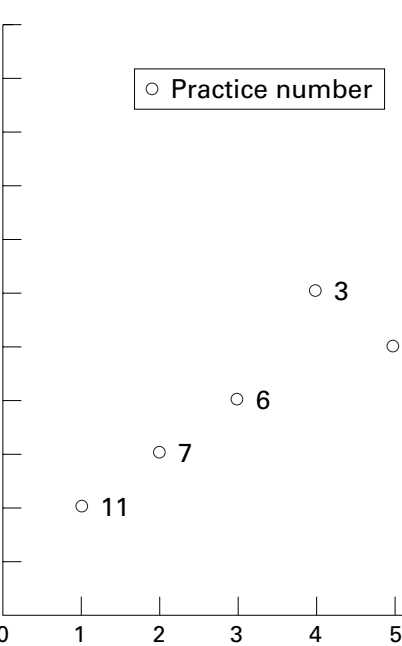

$\circ 5$

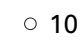

$\circ 9$

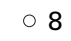

Figure 1 Relation between prescribing of tranexamic acid and/or mefanamic acid and referral to secondary care $(n=11$ practices). Spearman's rank correlation $=0.38, n=11$, $p>0.05$.

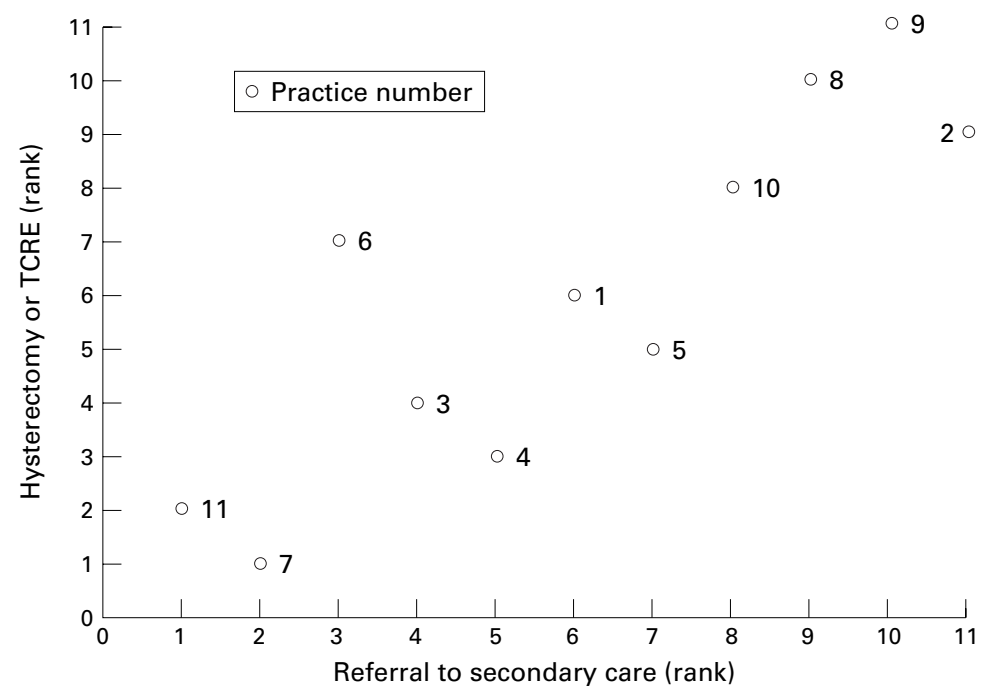

Figure 2 Relation between referral to secondary care and operative procedure $(n=11$ practices). Spearman's rank correlation $=0.86, n=11, p<0.05 . T C R E=$ transcervical endometrial resection. mean annual rate of menorrhagia in women aged 30-49 years registered with these practices was 25.8 per 1000 women per year; (this ranged across practices from 17.1 to 31.0 per 1000 per year).

Table 1 summarises the management of women in primary and secondary care. Nearly one in six women, $143(16.2 \%, 95 \%$ CI $13.7 \%$ to $18.6 \%$ ), consulting with menorrhagia received no active treatment (drug, referral or secondary care investigation/operation). Almost a quarter of women, $202(22.8 \%, 95 \%$ CI $20.1 \%$ to $25.6 \%$ ), received no drugs for their menorrhagia, while $243(27.5 \%, 95 \%$ CI 24.5 to $30.4 \%$ ) women were prescribed other drugs as treatment for menorrhagia, (such as hormone replacement therapy and oral contraceptives).

The mean annual referral rate to gynaecology for menorrhagia in the 11 practices was 9.0 per 1000 women aged 30-49 years per year, (ranging across practices from 6.9 to 14.0 per 1000 per year). Once referred nearly half of women, $143(42.9 \%, 95 \%$ CI $37.6 \%$ to $48.3 \%$ ), were operated on.

The operative rate in this study was 44 per 1000 women consulting with menorrhagia per year. This rate was lowest in women aged 30-34 years, (35 per 1000 women per year), and highest in women aged 40-44 years, (52 per 1000 women per year). Approximately 1 in 10 hysterectomies, $14(10.2 \%, 95 \%$ CI $5.1 \%$ to $15.3 \%$ ), and 1 in 5 transcervical endometrial resections $4,(18.2 \%, 95 \%$ CI $5.2 \%$ to $40.3 \%)$, were performed in the private sector.

RELATION BETWEEN MANAGEMENT IN PRIMARY CARE, REFERRALS AND OPERATIONS

Women referred to a gynaecologist were 2 significantly more likely to have been investigated and to have received tranexamic acid and/or mefenamic acid in primary care (table 2). Approximately one in seven women referred and subsequently operated on received no medical treatment in primary care (table 2). Women operated on after referral were no more likely to have received tranexamic acid and/or mefenamic acid in primary care than those not operated on after referral (table 2).

$2 \circ$ BETWEEN PRACTICE DIFFERENCES

There was an almost ninefold variation in tranexamic acid prescribing, a twofold variation in referral and a nearly threefold variation in hysterectomy (table 1). Figure 1 shows the relation between the rate of prescribing of tranexamic acid and/or mefenamic acid and the rate of referral to gynaecology. This correlation is not significant, but in all but one practice, high prescribing of these drugs was associated with high referral to secondary care. There was a significant positive correlation between rate of referral to gynaecology and rate of hysterectomy or transcervical endometrial resection (TCRE) (fig 2).

SECULAR TRENDS

There was a significant increase over the four year period in the number of women prescribed tranexamic acid $\left(\chi^{2}\right.$ for trend $=21.0$, 


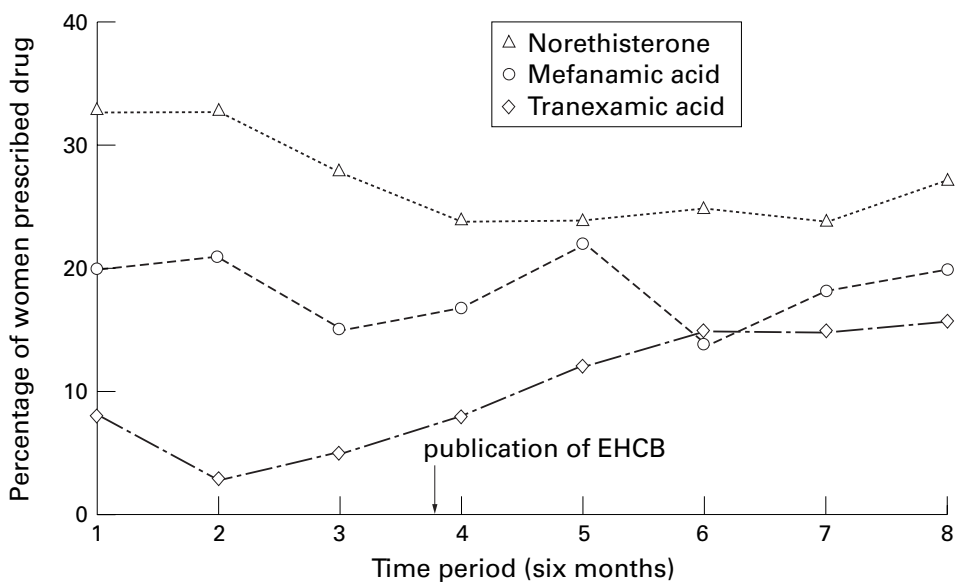

Figure 3 The rates of prescribing of tranexamic acid, mefanamic acid and norethisterone for women consulting with menorrhagia between April 1994 and April 1998. EHCB = Effective Health Care Bulletin.

$\mathrm{df}=1, \mathrm{p}<0.001$ ) (fig 3). However, there was no significant change in the number of women prescribed mefenamic acid $\left(\chi^{2}\right.$ for trend 0.04 , $\mathrm{p}=0.85)$ or norethisterone $\left(\chi^{2}\right.$ for trend 2.4 , $\mathrm{p}=0.12)$

\section{Discussion}

This study demonstrates scope for further improvement in investigation and prescribing for menorrhagia in primary care. There is substantial between practice variation in prescribing, investigation, referral and operation. A positive relation was found between referral and operation, suggesting the decision to refer has a major impact on the likelihood of a woman being operated on in secondary care. No evidence was found to support the hypothesis that effective prescribing in primary care might lead to reduced referral and hysterectomy rates. ${ }^{1}$ In fact women referred were more likely to have been prescribed tranexamic acid and/or mefenamic acid than those not referred.

IMPACT OF EFFECTIVE HEALTH CARE BULLETIN The impact of the publication of the Effective Health Care Bulletin "The Management of Menorrhagia" 18 months into the study does not appear to be substantial (fig 3). Prescribing of tranexamic acid alone changed significantly, but only $16 \%$ of women received this drug in the last six month period. This is consistent with evidence that written instruction provided in isolation to general practitioners does not result in a change in clinical practice. ${ }^{11}{ }^{12}$ Whether more recent management guidelines on menorrhagia will have an impact on treatment and referral rates remains to be seen. ${ }^{4}$

\section{COMPARISON WITH PREVIOUS STUDIES}

The proportion of women who received no active treatment for their menorrhagia in a previous study in primary care was lower $(4.3 \%)$ than in the present study. ${ }^{13}$ The proportions of women referred (between $53.3 \%$ and $67.3 \%$ depending on severity of menorrhagia) and operated on (hysterectomy $21.8 \%$, endometrial resection $17.2 \%$ ) were commensurately higher in the earlier study. This is likely to be because this previous study, designed to investigate management decisions in menorrhagia, looked at a population of women selected by their general practitioner rather than all women consulting with menorrhagia. Levels of investigation and prescribing have improved substantially in the past five years; another study found that $15 \%$ of women with menorrhagia had a vaginal examination, $13 \%$ had a full blood count and $1 \%$ were prescribed tranexamic acid. ${ }^{2}$ However, the levels of prescribing of tranexamic acid and mefenamic acid in the present investigation fell well short of those cited in a recent survey of general practitioners' intended prescribing habits. ${ }^{14}$ This is consistent with the finding that general practitioners' self reported actions may not reflect what they actually do in practice. ${ }^{15}$

METHODOLOGICAL ISSUES

The main limitations of this observational study are random variation, and the inability to account for the influences of case mix and patient and doctor preferences for treatment on the management of menorrhagia. The fact that women referred were more likely to have received tranexamic acid and/or mefenamic acid may reflect higher case severity. Alternatively, it may be that general practitioners interested in managing menorrhagia are more likely to prescribe effectively and have a lower threshold for referral. Some of the observed variation in referral rates will be attributable to random variation; when referral numbers are small, real differences may be swamped by such variation. ${ }^{16}$ However, as the average number of referrals per practice in this study is at least 30, comparison of practice rates is valid. ${ }^{16}$ Lastly, it cannot always be established from general practitioner records alone when, relative to referral and appointment in secondary care, investigation and prescribing in primary care occurs.

\section{MANAGEMENT OPTIONS AND WOMEN'S} PREFERENCES

The large between practice variations in management suggest that doctor and patient case mix do have a considerable impact on investigation, prescribing and referral. Menorrhagia is a subjective diagnosis, and a woman's symptoms frequently do not correspond with documented blood loss. ${ }^{1}$ Qualitative research has established that women consult their general practitioner concerned about why their menstrual loss has changed and what the underlying reasons for this might be. ${ }^{17}$ It may be that women with menorrhagia could benefit from reassurance, rather than receiving drugs and being referred. Clinical guidelines suggest that up to one third of women may opt for a "watch and wait" strategy, although in the present study a lower proportion (16\%) of women followed this option. ${ }^{4}$

It seems too simplistic to suggest that more effective prescribing in primary care could, on its own, reduce referral and hysterectomy rates. The indications for hysterectomy have been described as a reflection of the interface between medicine and society, ${ }^{18}$ and substantial 
variation exists between rates in different countries and regions. ${ }^{6}$ The role of women's preferences for treatment and their impact on the decision to refer is considerable; $36 \%$ of women in one study expressed a strong treatment preference. ${ }^{19}$ Furthermore, women who expressed a preference for surgery were more likely to be referred, ${ }^{19}$ and those who received a hysterectomy for their menorrhagia had higher levels of satisfaction. ${ }^{13}$ The impact of menorrhagia on women's lives is not simply confined to their physical wellbeing. Recent work has shown that women rate the impact menorrhagia has on their family life higher than the impact on their physical health. ${ }^{20}$ Further work in the area of women's preferences and individual utilities will help resolve whether effective forms of medical management can lead to improved patient satisfaction and reduced rates of hysterectomy for menorrhagia.

\section{CONCLUSION}

Variations in investigation and treatment of menorrhagia in primary care persist and the decision to refer means that a woman has a significant chance of getting a hysterectomy. The relation between medical management, referral and surgery is complex. Improvement in referral and medical management were recently demonstrated in UK general practices that received an educational intervention of evidence-based guidance. ${ }^{21}$ Further exploration of the role of women's preferences, using information leaflets, video packages or more formally through utility assessment is also needed. Against this background it seems that there is still some scope for improvement in the investigation and medical management of menorrhagia in primary care.

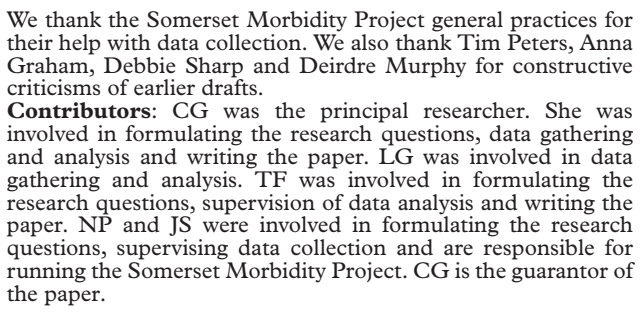
the paper.

Funding: Somerset Health Authority fund the Somerset Morbidity Project.

Conflicts of interest: none.

1 Effective health care. The management of menorrhagia. Effective Health Care Bulletin 1995;9:1-14.

2 Coulter A, Kelland J, Peto V, et al. Treating menorrhagia in primary care. An overview of drug trials and a survey of
prescribing practice. Int $\mathcal{F}$ Technol Assess Health Care 1995; 11:456-71.

3 Coulter A, Bradlow J, Agass M, et al. Outcomes of referrals to gynaecology outpatient clinics for menstrual problems: an audit of general practice records. Br F Obstet Gynaecol 1991;98:789-96.

\section{KEY POINTS}

- A prospective observational study examined the management of 885 women with menorrhagia in 11 Somerset general practices over four years.

- Large between practice differences in investigation and treatment were demonstrated between practices.

- A substantial proportion (38\%) of women are referred to secondary care and of these $43 \%$ have an operation.

- There is significant correlation between high referral and high operative rates, highlighting the impact of gate keeping in primary care.

- There is no evidence to suggest that prescribing tranexamic acid and mefenamic acid in primary care necessarily reduces referrals or subsequent hysterectomy.

4 Royal College of Obstetricians and Gynaecologists. The initial management of menorrhagia. London: RCOG Press, 1998 .

5 Irvine G, Campbell-Brown M, Lumsden M, et al. Randomised comparative trial of the levonogesrel intrauterine system and norethisterone for the treatment of idiopathic menorrhagia. Br f Obstet Gynaecol 1998;105:592-8.

6 Coulter A, McPherson K, Vessey M. Do British women undergo too many or too few hysterectomies? Soc Sci Med 1988;27:987-94.

7 Bonnar J, Sheppard BL. Treatment of menorrhagia during menstruation: randomised controlled trial of ethamsylate, mefenamic acid, and tranexamic acid. BMF 1996;313:57982 .

8 Working Party of the National Health Committee New Zealand. Guidelines for the management of heavy menstrual bleeding. Wellington: Ministry of Health, 1998.

9 Pearson N, O'Brien J, Thomas H, et al. Collecting morbidity data in general practice: the Somerset Morbidity

10 Allan K, Markwell D. MIQUEST Project Report. Leeds: NHS Executive, 1994

11 Oxman AD, Thomson MA, Davis DA, et al. No magic bullets: a systematic review of 102 trials of interventions to improve professional practice. Can Med Assoc F 1995;153: improve

12 O'Connell D, Henry D, Tomlins R. Randomised controlled trial of effect of feedback on general practitioners' prescribing in Australia. BMF 1999;318:507-11

13 Coulter A, Peto V, Jenkinson C. Quality of life and patient satisfaction following treatment for menorrhagia. Fam Pract 1994;11:394-401.

14 Task Force to Improve the Management of Menorrhagia. Survey of general practitioner's views on menorrhagia and treatment. London: Van der Post Public Relations, 1997.

15 Eccles M, Ford G, Duggan S, et al. Are postal questionnaire surveys of reported activity valid? An exploration using general practitioner management of hypertension in older general practitioner management of hyp
people. Br f Gen Pract 1999;49:35-8.

16 Roland M. Measuring referral rates. In: Roland M, Coulter A, eds. Hospital referrals. Oxford: Oxford University Press,

17 O'Flynn N, Britten N. Menorrhagia in general practicedisease or illness. Soc Sci Med 2000;50:651-61.

18 Lilford RJ. Hysterectomy: will it pay the bills in 2007? Treatment of choice for cancer, but a choice of treatment for menorrhagia. BMF 1997;314:160-1.

19 Coulter A, Peto V, Doll H. Patients' preferences and general practitioners' decisions in the treatment of menstrual disorders. Fam Pract 1994;11:67-74.

20 Shaw RW, Brickley M, Evans L, et al. Perceptions of women of the impact of menorrhagia on their health using multi-attribute utility assessment. Br $\mathcal{F}$ Obstet Gynaecol 1998;105:1155-9.

21 Fender G, Prentice A, Gorst A, et al. Randomised controlled trial of educational package on management of menorrhagia in primary care: the Anglia menorrhagia education study. BMF 1999;318:1246-50. 